\title{
YOUTUBE AS A NEW MEANS OF MARKETING COMMUNICATION
}

This paper discusses a new trend in marketing communication represented by a new generation of YouTubers. The target group, young people aged 12-16, is absorbed in following the YouTubers who set the trends in shopping; not only what one should buy but also when. There is often some kind of cooperation between the YouTubers and some of the well-known companies that provide sample bags with their products for the YouTubers for free. This paper analyzes the Czech YouTube environment, YouTube blogs from channels in English and the results of a questionnaire survey which was conducted on a sample of students who could be described as the Generation Y.

Keywords: Trends, Marketing communication, YouTube, Internet.

\section{Introduction}

After the printing press was invented, it took more than another 400 years until the newspaper spread out massively and the potential of this invention was maximized. Whereas in the past, the newspaper was accessible only to the elites, the 19th century brought the daily press to all social classes. Rotary presses churned out high circulation of newspapers even several times a day.

When the then Czechoslovakia was first connected to the internet on February 13, 1992, the lay public was practically unaware of such network. On February 14, 2005, exactly 13 years and one day later, the YouTube server designated for sharing home-made videos was activated. The internet was a massively used medium in the Czech Republic at that time, referred to as "the gravedigger" of the classic newspaper printed on paper.

More than 10 years later, some refer to the YouTube server as "the gravedigger" of another, today classic, medium, the TV. The thing is that over the 10 years of its existence, the server became a fundamental means of mass communication, which is, unlike the classic media, available to general public and thus creates a completely new platform of media communication.

\section{YouTube}

YouTube is the biggest internet server for sharing videos. It is a place where everyone can upload, share, watch and also comment on originally created videos. A place where ordinary people can, practically without any need of investment, compete with big media companies and corporations not only in terms of viewer ratings but also in terms of the number of loyal followers.

The aim of this paper is to closely examine the group of Czech users of this server, the YouTubers, who publish their videos on a regular basis for a specific group of followers, usually teenagers aged 12-16. However, older viewers or followers are no exception. A recent survey of TNS Aisa company showed that there is a greater hit rate from YouTube than from any other classic Czech TV channel for viewers aged 15-35 [1]. This makes YouTube a very perspective marketing-communicative channel and YouTubers then often become a new kind of media celebrities.

When compared to the classic TV, YouTube provides a countless number of plus points for the young generation ranging from the possibility to play the video "on demand" or the possibility to use the shortened format of videos to the possibility to make one's own videos as mentioned above. One can make "friends" or rather a portfolio of faithful followers and can exercise their typical influence of the opinion leader or, as used in the YouTube environment, influencer on them [2].

Even though Czech YouTubers have been uploading their videos on YouTube approximately since 2010 and those from the USA started even earlier, the massive expansion of video blogs or blogs can be perceived in the Czech Republic only in the last two years. Vlogging, following the lead of the USA, became a massive trend in the Czech Republic. However, unlike the well mapped USA market, the Czech environment lacks a relevant and independent analysis. It is necessary to determine the situation on the domestic market and also to consider whether the issue touches also other areas such as the concept of sustainability or others. Such is the aim of this paper.

\footnotetext{
* Lucie Sara Zavodna, Jan Zavodny Pospisil

Department of Applied Economics, Philosophical Faculty, Palacky University in Olomouc, Czech Republic

E-mail: jan.zavodny@upol.cz
} 


\section{Methods}

The Czech part of the research was conducted in a form of an analysis of 15 Czech YouTubers with channels with more than 100,000 followers. All of the channels belong to natural persons. In most of the cases the channel belongs to one YouTuber, only one channel belongs to two persons. Ten videos on various topics and from various dates were randomly chosen from each channel. $20 \%$ of the chosen YouTubers were men. The duration of the spots ranged up to 10 minutes. The channels were chosen from a top list published by the Socialblade web platform.

Moreover, a summary questionnaire called Media in the life of students was created and was used for collection of questions of students who belong to the Czech Generation $\mathrm{Y}$ - year of birth 1987-1996 [3]. The questionnaire was used for collection of several data, yet one part was focusing directly on watching YouTube. The questionnaire was accessible in Google Docs, from February to June 2016. Altogether, 743 respondents completed the questionnaire, 33\% of which were men.

\section{YouTubers in the Czech Republic}

The Czech language version of YouTube was launched October 9, 2008 [4]. Since then, a dynamic increase can be seen not only in daily access to the website and the number of watched videos but also in the number of uploads of users' videos as well as in the number of individuals uploading their videos [5]. The video clip called Patnactiny (My fifteenth birthday) of the all-girl band called LuSteLa is said to be one of the first Czech videos that spread virally via YouTube. It was uploaded to YouTube in March 2010 and up to now has almost 1.4 million views [6]. The quality of the content was not the main reason why the video spread virally; even though it was meant to be a true, serious video clip, it became a self-parody to some extent and thus fulfilled one of the criteria for becoming a viral video [7].

First video bloggers started to upload their videos to YouTube the same year. One of the first videos were the specific beauty videos [8] in which young female bloggers usually review cosmetics, clothes or fashion accessories. At that time, young bloggers of the opposite sex most often uploaded videos in which they shot themselves while playing computer games. Such bloggers are usually also called Let's Players [9]. An increase in users' videos on various topics the main aim of which is to amuse the viewers and to some extent also fulfill the same function as blogs in the past can be seen only since 2012 in the Czech Republic

The format mentioned above with all its characteristics gave birth to a new media genre called blog [10]. It is a multimedia genre the core of which forms a video recording starring the video maker himself or herself. The main speech format used for addressing the audience is monologue [11]. The author of the video creates its content with the monologue and also subsequently edits the video, which is typical of this genre as well, and thus determines the final form of the vlog. Even though such videos are designed as an improvised monologue, the actual form of the vlog is a result of a thorough choice made through editing the recording. Therefore the vlog as a genre cannot be considered a pure improvisation.

Speaking of other characteristics, the vlog reflects the internet environment and allows almost unlimited spreading of the original information within the hypertext principle [12]. The bloggers make use of this by adding further information below the video, by posting links to social networks but also by leading a dialogue through interaction with other users who comment on the published video.

One of the characteristics of vlog as a genre is the possibility of indirect interaction with the audience. Such interaction is usually realized through the possibility to comment on the video in the space below as mentioned above. The author of the video can communicate with the viewers through textual response to such comments. Vloggers can also respond to comments through other vlogs and the comments can also serve as a subject of another vlog. Social networks are another possible form of interaction with the audience. The most commonly used social network in the Czech Republic, Facebook, is simply not enough for the YouTubers of today. They often use also other social networks such as Ask, Snapchat, Instagram and to a limited extent also Twitter.

The audience is thus connected to the YouTubers through several channels. The sense of togetherness with the YouTuber on the one hand and the participation of the audience on the vlog on the other delude the authors as well as the audience into thinking of a collective community, often referred to as a family [7].

Vlog as a genre also introduces a specific language [10] or rather slang to the media scene, which introduces new anglicisms into Czech. Vloggers pronounce English words with Czech accent such as haul /ho:1/, ask /a:sk/, tag /ta:k/, DIY / di:a:iwa:i/, stream /stri:m/, unboxing /anboxink/, merchandising /me:rt / and so on even though there are equivalents for such words in Czech as well, sometimes even several equivalents. All Czech vloggers use such specific anglicisms to some extent. The pronunciation together with the English word order influences their speech, which turns into a new slang form of Czech: Czenglish [12].

Borrowing of words and phrases from original American videos is to some extent symptomatic for Czech YouTubers because, in this case, they copy not only the complete form but often also the content of vlogs itself. Such content is then adapted to the Czech environment, which in some cases causes laughter or even disgust with some members of the audience. Some YouTubers also copy the categories of such genre or rather formats of vlogs. A wide range of vlog formats [13] can be found in the US while basically only six basic formats were adopted in the Czech environment. These are: videos about cosmetics or fashion (beauty), playing computer games (games), insight into YouTuber's life (vlog), shopping (haul, shopping), funny videos including challenges (fun) and also videos from the DIY category (DIY). 
Other categories, such as informative videos and instructions, a vast number of home videos and other fun videos can be found among the Czech YouTube videos as well. However, such videos lack the specific characteristics of the genre typical for YouTubers, who are discussed in this article, or rather do not have all the characteristic features of the genre.

\section{Czech Youtubers as a specific marketing tool}

Three years later if not more after the YouTubers in the US and their videos became a tool for profit generation on the part of the video makers themselves as well as on the part of various third parties, the same thing happened in the Czech Republic. YouTubers generate profit in the form of remuneration for placing the advertisement in the video with the growing number of unique views of videos or rather with the number of regular followers. The advertisement can have a textual, graphical or audiovisual form and is placed in the videos by the provider of YouTube, Google company, in accordance with the clients' demands [14]. The author of the video gains 55\% of the amount of money the advertiser paid for the advertisement for every thousand views of the advertisement before the author's video [15]. The remaining $45 \%$ goes to Google. The actual amount of remuneration for a given number of views depends on such factors as the type of the video, the quality of the content or its presentation by choosing the appropriate view [16]. The author himself or herself or rather the number of regular followers of his or her channel is also a very important factor. In the Czech Republic, the turning point when YouTubering becomes more than just a small extra income is having at least 100,000 followers [15].

The quoted figure cannot be, however, confirmed from a reliable source because Google does not publish the amount of remuneration for placing an advertisement in videos. It might be a company policy but the way the amount of remuneration is calculated is the essential factor limiting the determination of an actual amount of money for a specific YouTuber. The remuneration is determined according to the investments of the advertisers, yet the factors listed above have an essential influence. At least some general knowledge about the profitability or rather rate of return of chosen YouTubers and their channels can be gained through the American project SocialBlades. The authors of this site publish data certified directly by Google [1] This data show which YouTubers and which YouTube channels and sites are most important in a given country with respect to several criteria such as the number of followers, viewer ratings and SB Score. The SB Score is an indicator based on a further evaluation of the criteria by the Social Blade company and is similar to the credit rating of individual countries. A generally estimated data about the monthly or yearly profit of a channel or a YouTuber is also stated as a part of the SB Score. ViralBrothers, the channel with the most views in the Czech Republic, has $\mathrm{B}+$ rating and an estimated income ranging from 1,7 to 27,6 thousand USD [17].
The money paid to the YouTubers by the commercial companies for the cooperation between the two of them represent another way of generating profit. The principle of such cooperation is based on the placement of brands of promoted products into the content of the video. It can be a classic testimonial [18], a type of advertising appeal when an important personality mentions the qualities of a product or a brand. A personality, in this case, means the author and at the same time the protagonist of the video, the YouTuber.

It is more and more common, though, to place the product directly in the video so it becomes a more or less natural part of the plot. The YouTuber can either directly admit, for instance in the text about the video or verbally, that he or she placed the product in the video for commercial purposes or it can be some kind of a hidden advertisement. For instance, the Czech YouTuber Michaela Nguyen using the nickname Stylewithme promotes the Mattoni brand in one of her videos. In this video, she accepted a challenge from a fan to drink something in one go and in order to fulfill the challenge, she drank a bottle of water of this brand. From the ethical point of view of the advertisement, there is a problem with the video because of the problematic concept of the scene which gives the impression that Nguyen drinks from a bottle randomly found in the house. However, as the author herself admits, she made an agreement with the Mattoni brand which states that she will promote their products [7].

Such example shows that the new phenomenon of commercial communication within the YouTube environment becomes more and more common. The cooperation between the vloggers and the companies or brands is very promising not only because of the financial attractiveness for the YouTubers but also because of the change in attitude of the young generation to the classic media. As some vloggers confirm [7], the companies sometimes exert pressure on the final form of the video which means that they try to persuade the YouTubers to place the product or brand in the video in a way that will minimize the injury to their image.

There are no hard and fast rules applying to the commercial communication of brands these days in the Czech Republic, which means that the final form of the cooperation on the vlog falls within the competence of the vlogger and the advertiser. It is also true that the willingness to let the commercial partner meddle with the content of the video is different with each YouTuber. It is supposable that the relationship between the YouTuber and the commercial subject might be considerably unbalanced and is usually characterized by the difference in the interest of the parties.

The reasons listed above as well as others led to the constitution of specialized agencies that mediate the cooperation between YouTubers and commercial subjects. These agencies also determine the basic definition of the form of the cooperation to some extent and jointly form the related market space for the commercial realization of YouTubers' additional product sale and promotion of their personal presentation including the presentation of the whole market segment of vloggers. At the present time (7/2016), there are 2 specialized agencies in the Czech Republic, Get Boost and TUBRR, that help YouTubers with the implementation of events for fans, 
provide technical consultancy and most importantly negotiate the final form and terms of the relationship between YouTubers and the commercial subjects [7]. The TUBRR agency also participates in the measurement of YouTubers' commercial value [19].

Other subjects, besides the agencies mentioned above, that make use of the new environment of YouTube, vloggers and related market segments are arising as well. Even vloggers themselves sometimes make use of the related commercial opportunities: they sell their own merchandise or in cooperation with other commercial subjects co- organize special conferences for YouTubers and their fans or at least host such conferences. There are 3 such meetings in the Czech Republic at the present time - CineTube, 4FANS and YouTubering.

CineTube is a meeting of Czech and Slovak YouTubers with the screening of their 2 - 5 minutes long premiere videos on a big screen in a cinema. This meeting takes place 4 times a year in various cities of the Czech and Slovak Republic. The advance price of a ticket is 99 CZK and gate price is 149 CZK [20].

4FANS is a two-day Czech conference for YouTube fans. It takes place in Prague. Minors under 15 years of age need the consent of next friend for attendance. The advance price of a ticket is $300 \mathrm{CZK}$ or 700 for VIP zone where the odds of meeting a YouTuber are better. A beauty contest Miss Beauty is a part of the 2017 meeting. There is also an afterparty in a club in the evening [21].

YouTubering is a one-day Czech festival that takes place in two cities - Prague and Brno. The price of a ticket is 599 CZK. According to the organizers, this festival arose from the dream of having a festival for the Generation Z. The festival started in 2015. There are several stages and stands in different sections according to the focus of the YouTubers - gaming, fashion, entertainment, and music [22].

\section{YouTubers outside the Czech Republic}

A similar comparative analysis of domestic and foreign YouTube environment is neither within the compass of the scope of this article nor its aim. Yet having an insight into the foreign, primarily North American, scene of YouTubers is paramount for the Czech Republic. As was mentioned above, Czech vloggers to a great extent copy their American colleagues who are their basic inspiration. It is also true that the North American vlogger space is at least three years ahead of the Czech one regarding the realization of first vlogs. It is thus essential to perceive the American vlogger market as an important space that enables prediction of the development of domestic scene including setting new trends.

It might be very interesting to look back into the statistics of the SocialBlade project that makes a list of the most profitable YouTubers or YouTubers with most views. While there are mainly amateurs together with the Czech mutations of foreign formats of videos, such as the Real-life superheroes (RLSH) phenomenon [23], in the top ten in the Czech Republic, the situation in the North America is different.

Five of the top ten most profitable [1] channels in the US are official channels of various artists who release their records in cooperation with two or three main music publishing companies Universal Music Group, Sony Music Entertainment and since August 2015 also Warner Music Group [24]. These companies, together with the owner of YouTube, Google, create a specific environment for sharing video clips under the VEVO trademark [25]. The rest of the top ten channels belongs to professionals as well, all of them fall into the category of entertainment [1].

The professionalization of videoblogs is at a high level in the US while this process is only at the beginning in the Czech Republic. For instance, YouTube provides several professional studios for YouTubers with more than 5 thousand followers [26]. Online video artists who have at least 5,000 subscribers can utilize the studio space and professional equipment free of charge. The facilities also host workshops and social events to YouTube creators. Before shooting videos, the creators can sign up for tutorials and learn how to use the equipment, which includes cameras, microphones, green screens and editing stations [27]. Such studios provided by YouTube are being opened all over the world; the one closest to the Czech Republic is the YouTube studio in Berlin.

Channels offering various kinds of entertainment are the most dominant regarding profit and the number of views in both Czech and American YouTube environment. This might seem as a unifying element for both countries, however, it is not. According to the definition of entertainment as a genre, there are several forms of entertainment, in particular noble, harmless and pulp entertainment [28], and each of these has a different effect on the percipient. Several significant differences can be found between the most important YouTube channels in the Czech Republic and in the US according to such stratification of entertainment. According to another analysis, the entertainment in the US is harmless while the channels with the most views in the Czech Republic offer mainly pulp entertainment. Another difference is that among the American YouTubers, vloggers who also talk about serious topics in their vlogs are very popular. For instance, a famous American vlogger JennaMarbles, whose full name is Jenna Nicole Mourey, often focuses on topics that are important or seen as controversial in the society [29-30].

That gives a scope for further research that could discover the cause of the difference of the phenomena. One of the assumptions claims that this could be caused by the delayed development of YouTube environment mentioned above because the Czech YouTubers have not reached such a level of professionalism as their colleagues in the US. In general, the North American vlogger segment can be described as very similar to the Czech one because it is inspired by its American opposite.

There is also a conference for YouTubers called Vidcon in the US, similar to the Czech Republic. It is held in Anaheim, California. There are three types of tickets starting from 150 USD. In 2015, over 21,000 fans, creators, and industry leaders got together on several stages. Fans of YouTubers such as DulceCandy, Amanda Steele, Sprinkle of Glitter, Fleur De Force, Kandee Johnson and Bretman Rock can enjoy themselves during panels with their favorite creators. In the gaming stage, there are panels and discussions about how to 
create good gaming content, live gameplay with top creators, etc. There are also various workshops and seminars. Seminar series arm attendees with proven strategies, secrets, and techniques to drive more viewers, engagement and revenue across every significant social video channel [31].

\section{Results of the research}

The evaluation of the questionnaire brought very interesting findings. In the eyes of students, YouTube is one of the most important media for the collection of information. YouTube thus equals radio according to the respondents. From all the respondents, $18 \%$ does not watch TV at all and $34 \%$ only several times a month - Table 1.

Important Sources of Information According to the Respondents

Table 1

Which of the following media do you consider to be the most important source of information?

\begin{tabular}{|l|c|c|}
\hline TV & 291 & $39 \%$ \\
\hline Radio & 95 & $13 \%$ \\
\hline Printed Media & 178 & $24 \%$ \\
\hline Social Networks & 436 & $58 \%$ \\
\hline YouTube & 107 & $14 \%$ \\
\hline Internet News Servers & 616 & $83 \%$ \\
\hline Other & 9 & $1 \%$ \\
\hline
\end{tabular}

The respondents most frequently marked the credibility by the mark 4 (where 1 was used to mark the most credible source). This shows that students are aware of the low credibility of this medium. The best marks and thus the most credibility were given to Internet news servers and Printed media. In total, $92 \%$ of respondents think that the medium of the future, i.e., the most important medium in the years to come, will be the internet. Only $3 \%$ of respondents think that way of television. A very interesting finding is that $28 \%$ of the respondents do not read printed newspaper at all - Table 2.

The Credibility of Media as Marked by the Respondents

Table 2

Mark the credibility of the following media the same way as in school (1 most credible, 5 least credible)

\begin{tabular}{|l|c|c|}
\hline & Mode & Mode frequency \\
\hline TV & 3 & 247 \\
\hline Radio & 2 & 278 \\
\hline Printed Media & 2 & 258 \\
\hline Social Networks & 4 & 264 \\
\hline YouTube & 4 & 277 \\
\hline Internet News Servers & 2 & 310 \\
\hline
\end{tabular}
that they do not watch YouTubers at all. The rest said that they watch them out of boredom (14\%) or because they are interested in new trends ( $14 \%$ ) or in the life of the YouTubers (7\%); only 9\% of respondents watch YouTubers instead of television. Regarding the frequency of watching YouTube, $45 \%$ of respondents said that they watch YouTube videos regularly every day, $5 \%$ watch videos every day, $4 \%$ every time when the YouTuber they like publishes a new video. Only $1 \%$ of the respondents said that they have their own videoblog, $5 \%$ write their own blog.

Fragmented perception of information is characteristic for the internet. People usually do not focus on only one activity, which, in this case, means watching a video. Respondents stated, that they often eat (33\%), watch other things on the internet ( $23 \%$ ), study or read $(12 \%)$ and shop (4\%) while watching videos. Shopping online while watching a YouTuber may thus easily lead to buying items the YouTuber promotes. Only $8 \%$ of respondents stated that they watch only the chosen video. The respondents do not differentiate a YouTuber from a Streamer; more than $60 \%$ of respondents could not explain these two terms.

From the point of view of marketing, it was very interesting to find that $14 \%$ of the respondents have already bought an item because it was recommended by a YouTuber. If we focus only on respondents who watch YouTubers, the number rises to $27 \%$.

\section{Conclusion}

Making YouTube videos has become quite profitable for many artists as there are currently more than 1 million channels earning revenue through YouTube. Thousands of channels are making six figures annually through selling advertising, and partnering with companies by making videos promoting their products. One billion unique users visit YouTube each month and watch 6 billion hours of video [27].

The YouTube environment turned into a completely new market; its domestic growth potential can be predicted according to the situation in North America. From the point of view of YouTube as a medium and the vlog genre as a means of marketing communication, there is a scope for making use of these for now. Vloggers stand a good chance of connecting with groups of people that, according to the surveys mentioned above, diverge from the old media including classic television. Vlogging is thus a perspective means for connecting with such groups.

The value of YouTube or rather vlog is apparent even in groups that are not a part of the target group. The findings of our research showed that the current university students, often referred to as the Generation Y, perceive YouTube as one of the most important media for the collection of information. However, when compared to the uncritical reception of information from YouTube by the Generation $\mathrm{Z}$, the target audience of many vloggers, the representatives of the university students doubt the credibility of this medium. Nevertheless, 
this does not mean that they would not buy the products promoted by a vlogger.

The research also confirmed the results of other researches that show a considerable departure of the young generation from the television. YouTube and vloggers thus fill up the free time of students the same way television did in the past. The fact that some TV stations try to cooperate with the vloggers is rather an example of a vain effort to keep a part of the audience. Trends of the young generation are not set up by the television as was typical for a long time but rather by the vloggers who are only a few years older. The question is who sets up trends for the vloggers, which leaves room for follow-up research.

\section{References}

[1] SocialBlade: YouTube. Retrieved from: http://socialblade.com/youtube/top/country/cz

[2] PATTERSON, K. et al: Influencer: The New Science of Leading Change. McGraw-Hill Education, 2013.

[3] MCCRINDLE, M. et al: Generations Defined. Ethos, 18.1: 8, 2010.

[4] POLESNY, D.: YouTube in Czech Language: Starting Today, the Reality (in Czech). Retrieved from: http://www.zive.cz/Bleskovky/YouTubecesky-od-dnesniho-dne-realita/sc-4-a-143974/default.aspx

[5] BILKOVA, L.: Czech YouTube: Television Channel Number one for Youths. And not only for them (in Czech). Retrieved from: http:// googlepresscz.blogspot.cz/2014/09/cesky-youtube-televizni-kanal-cislo.html

[6] GREGOR, J.: Who Appreciate it? (in Czech). Retrieved from: http://www.respekt.cz/tydenik/2010/6/kdopak-to-oceni

[7] JANAUEROVA, B.: Entertainment without End: The Children's Room had Long since Penetrated YouTuber, now beginning to Conquer and Businesses. Or is it vice versa? (in Czech), Respekt. Praha : Economia, 2015, 26(48), 40-43. ISSN 0862-6545.

[8] NAM, S.: "Let's Play": Guck mal, wer da spielt: Die neue Youtube-Masche - Netzwirtschaft - FAZ”. Frankfurter Allgemeine Zeitung (in German), 2013.

[9] FROBENIUS, M.: Beginning a Monologue: The Opening Sequence of Video Blogs. J. of Pragmatics, 2011, 43.3: 814-827.

[10] BETANCOURT, R.: Genre as Medium on YouTube: The Work of Grace Helbig. The J, of Popular Culture, 2016, 49.1: 196-223.

[11] OBLAK, T.: The Lack of Interactivity and Hypertextuality in Online Media. Gazette, 2005, 67.1: 87-106.

[12] SPARKLING, D.: English or Czenglish?: How to avoid Czechism in English (in Czech), 2nd ed., Praha: Statni pedagogicke nakladatelstvi, 1991, 274 p. ISBN 80-04-25969-3.

[13] LAVAVESHKUL, L.: How to Achieve 15 minutes (or more) of Fame through YouTube. J. of Intern. Commercial Law and Technology, 2012, 7: 370.

[14] Google: Help for AdWords. Showing ads in Videos and on Websites with Videos. Retrieved from: https://support.google.com/adwords/ answer $/ 2404253$ ? $\mathrm{hl}=$ cs\&ref_topic $=3119140$

[15] BARTONICKOVA, T.: YouTube Blogs about Beauty as Lucrative Business (in Czech), Markething.cz. ISSN 1805-4991. Retrieved from: http://www.markething.cz/youtube-blogy-o- krase-jako-lukrativni-byznys.

[16] Google: Help for YouTube. Guidance on Advertiser-friendly Content. Retrieved from: https://support.google.com/youtube/answer/6162278

[17] SocialBlade: ViralBrothers. Retrieved from: http://socialblade.com/youtube/user/ viralbrothers

[18] MARTIN, B. A. S., WENTZEL, D., TOMCZAK, T.: Effects of Susceptibility to Normative Influence and Type of Testimonial on Attitudes toward Print Advertising. J. of Advertising, 2008, 37.1: 29-43.

[19] TUBRR agency. Retrieved from: http://start.tubrr.net/reklamni-kampane-s-youtubery/

[20] Cinetube conference (in Czech). Retrieved from: cinetube.yt

[21] 4fans conference (in Czech). Retrieved from: www.4fans.cz

[22] Youtubering (in Czech). Retrieved from: www.youtubering.cz

[23] HBO Documentaries. Superheroes: Interview with Michael Barnett. Superheroes. 2011. Retrieved from http://www.hbo.com/documentaries/ superheroes/interview/michael-barnett.html

[24] FlanAGAN, A.: VEVO, Revivified, Looking to Strike a Deal with Warner Music Group. Billboard. 2015. Retrieved June 26, 2016.

[25] HANDL, J.: VEVO Music Video Server Launched (in Czech), Lupa.cz. 2009. Retrieved from: http:// www.lupa.cz/clanky/hudebnivideoserver-vevo-odstartoval/

[26] Youtube space. Retrieved from: https://www.youtube.com/yt/space/

[27] New York Daily News: YouTube Open Professional Studios. Retrieved from: http:// www.nydailynews.com/new-york/youtube-openprofessional-studio-nyc- creators-article-1.1974332

[28] BAROSEK, J., DANKOVA, H.: J. and School: A Guide for Teachers of Media Education (in Czech), 2008, Frydek-Mistek : Vaclav Danek. 
[29] ONDREJKOVA, D.: Is the Blonde Funny or Stupid?: American Blogger Breaking Myths about Blondes (in Czech). Reflex. 2012, 5. 11. 2012, ISSN 1213-8991. Retrieved from: http://www.reflex.cz/clanek/lajk/48380/je-ta-blondynka-vtipna-nebo-blba- americka-blogerka-bori-myty-oplavovlaskach.html

[30] WOTANIS, L., MCMILlAN, L.: Performing Gender on YouTube: How Jenna Marbles Negotiates a Hostile online Environment. Feminist Media Studies, 2014, 14.6: 912-928.

[31] About VidCon. Retrieved from www.vidcon.com. 